\title{
A Syntactic Analysis of the Sentence Pattern in Online News Article at The Jakarta Post's Website
}

\author{
Nur Rahmawati ${ }^{*}$ and Siti Rachmi ${ }^{2}$ \\ ${ }^{1,2}$ Department of English Language Studies, Universitas Hasanuddin, Makassar, Indonesia \\ *rahmasarianingsih@gmail.com
}

\begin{abstract}
This study aimed (1) to know the sentence patterns used in news desk at The Jakarta Post's website and (2) to find out the construction of the sentence patterns in news desk at the Jakarta Post's Website. The method of this research was descriptive qualitative. The data was the one clause sentences from online news articles posted in The Jakarta Post's website. The sentences were taken randomly from the articles posted in the month of October and November 2021. The analysis was oriented to syntactic analysis. The object is the sentence pattern that covers the Subject, Predicate, Object, Complement and the Adjunct. The research findings showed that the sentence pattern in online news articles at The Jakarta Post's website is manifold. There were 9 sentence patterns found and among these 10 sentence patterns, four include the basic sentence pattern, for example, SPA and SPC while another did not. The findings also showed that the constructions of the sentence patterns in online news article The Jakarta Post Website were theoretically structured.
\end{abstract}

Key words: Sentence pattern, Syntactic analysis, The Jakarta Post.

\section{Introduction}

As human, we need to communicate with each other, since we are all social beings, and to do so, we absolutely need language. Language itself might be manifold. One of language's existence is in written form. The common or the familiar written form that every person may need is an article. An article is a kind of writing which is usually published in a newspaper or magazine. It often contains information about news, entertainment, health, lifestyle and so on. The article which contains news is supposed to give readers the accurate and actual information and the up to date information about their circumstance or indeed overseas where it is absolutely needed by them. However, it is not ruled out the possibility that an article of news may be a hoax too. Then people must select the way in getting their information. So, to fulfil human's necessity of news, Newspaper is one of a quite good way to achieve that accurate and actual information or news

Traditionally, a newspaper is a printed media containing written information about current event. It is one of information sources and a kind of written mass media as well, which is issued daily or weekly that consist of several issues. It is to make indirect communication and interaction between the information sources and the receivers by using such folded papers. Nevertheless, in this present day, people can communicate and get the information they need easily without waiting for the newspaper's distribution time by the rapid growth of technology which presents 
websites on the internet. In other words, Newspaper's news is also published on a website. For that reason, The Jakarta Post as one of a well-known newspaper in Indonesia, not only issued their news through newspaper but also through websites or in other word, online news. The Jakarta Post posted their news on their website in purpose for the local readers or Indonesian and international readers. The existence of English as the international language held an important role here. Therefore, The Jakarta Post uses English as medium in serving their news to the readers. The news itself is served in some sort options of news to read. They are "Indonesia", "Business", "World", "Opinion", "Culture", " "Travel", "Multimedia", "Sport", "Front Row", "Today's Paper", and "More". In this case, the writer chooses online news article from "Indonesia" in referring to the data, to analyse the sentence pattern. Thus, the writer chooses news that is posted in "Indonesia". All articles posted in "Indonesia", are all written to release news or information about Indonesian.

Sentence itself has been classified in many ways. Type of sentence by the major uses in communication for example, it has four kinds in it. They are declaratives, interrogatives, imperatives, and exclamatives. Meanwhile when we look at the type of sentence by its structure, or syntactically, we will find four of these, simple sentence, complex sentence, compound sentence, and the combining of those complex and compound sentence which is called compound-complex sentence. However, not all of the patterns of these sentences would be analysed, the writer only focused on the sentence which categorized as one clause sentence or simple sentence.

Some published research in which the data are taken from The Jakarta Post had been conducted by some researchers. Regarding structure analysis, there are two published researches found. The research involved syntactic analysis [1] and word formation analysis [2]. The research which involved syntactic analysis was focused on the headline structure that was used in The Jakarta Post online news article. Meanwhile, the research which involved the word formation analysis was focused on how the words of headline news articles were structured. We might see that this research tends to that morphological one. From these two previous researches, headline news was the object that had been taken to be analysed. However, it is also important to know the structure of a sentence used in the article content of The Jakarta Post website article, as one of online newspaper that has been published internationally with their good English usage in their website and also as a biggest national newspaper in Indonesia itself. The writer chooses this website because this is the most popular English newspaper's website in Indonesia.

Based on the explanations above, the writer's interest is to focus on analysing the sentence pattern used in the article in order to know: (1) What is the sentence pattern used in news articles at The Jakarta Post's website? (2) How are the constructions of the sentence patterns found in news articles at the Jakarta Post's website?

\section{Theoretical Reviews}

\section{Syntax and Syntactic Analysis}

The term 'syntax', is from Greek "suntassein" which literally means 'to put in order' [3]. While traditionally, syntax refers to the branch of grammar dealing with the ways in which words, with or without appropriate inflections, are arranged to show connections of meaning within the sentence [3]. Syntax is also defined as the set of rules or principles that govern how words are put together to form phrases, well formed sequences of words [4]. Therefore we might say that syntax is a study of sets of rules. Those rules refers to the branch of grammar dealing with the ways in which words are constructed or arranged to build something bigger than that word, i.e. phrase and sentence, or the ways in which sentence is being curved up into smaller unit, i.e., phrase and word to show connections of meaning within the sentence.

Despite the definition of syntax itself, the scope of syntax also copes with the analyses [6]. The analysis which is done from a syntax perspective is a syntactic analysis or could be syntactic investigation. Syntactic investigation of a given language has as its goal the construction of a grammar that can be viewed as a device of some sort for producing the sentences of the language under analysis [7]. Furthermore, syntax, or syntactic analysis may be defined as: (a) determining the relevant component parts of a sentence and (b) describing these parts grammatically [8].

The definition of syntax or syntactic analysis above implies that we start from what is regarded as the largest unit of syntactic description - the sentence - and proceed until the small unit of syntax, namely the word. [6] Syntactic analysis might be done by using bracket and tree diagram. Using a tree diagram we can obtain a much clearer representation of a sentence structure [9]. Example of syntactic analysis by using tree diagram is as follows:

e.g. After visiting Milan, they decided that they must see Naples [10]

\section{Sentence}

A sentence is a group of words that makes a statement and can be followed by a period, question mark, or exclamation point [11]. [12] To be a sentence, a group of words must, (1) Have a subject (noun or pronoun; (2) Have a predicate (verb or verb phrase); (3) Express a complete thought. There are five elements that can be part of a sentence. They are subject, predicate, object, complement and adjunct. The sequences of these five elements are then known as a 


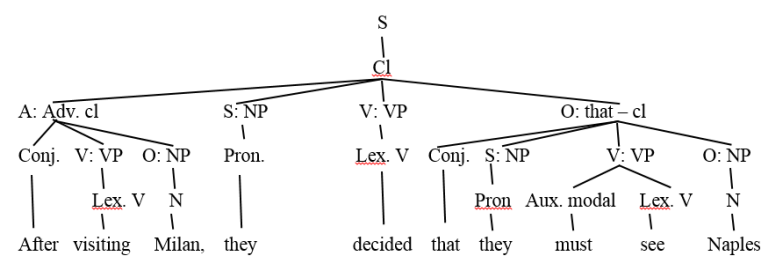

Figure 1. An Example of Syntactic Analysis

sentence pattern. In determining which should be a subject, predicate, object, complement or adjunct in a sentence we must consider some linguists theory that had been proposed to recognize each of those sentence patterns.

For the subject, which usually appears as the first pattern of a sentence, it is an element that precedes the predicate in the sentence [13]. Subject of a sentence tells us who performs the action denoted by the verb (i.e. who is the Agent), and on the other hand tells us who or what the sentence is about [9]. So to find out what the Subject of a particular sentence is we can ask 'Who or what carried out the action denoted by the verb?' and also 'Who or what is this sentence about?' Whereas to what filled the element of the subject, it includes the noun or pronoun that tells what the sentence is about [12]. After the subject appears the following element is usually filled by a verb, i.e. the predicate that describes what the subject is doing, then it is usually followed by an object, complement, or adjunct.

The object is the person or thing affected by the action described in the verb or predicate [14]. Object can be direct or indirect. A direct objects is often Noun Phrase (though not exclusively), their usual position is after the main verb and have a strong relationship with the verb that precedes them [9]. For example: His girlfriend bought this computer whereas an indirect object tells to or for whom something is done. There are also some syntactic characteristics for indirect objects [9]. Those are, indirect objects usually Noun Phrases; they cannot occur without a following direct object; indirect objects always precede direct objects; final syntactic characteristic of indirect objects is that, like direct objects, they can become the subjects of passive sentences. While a complement is the word or words that complete the meaning of verbs that expresses feeling, appearing, being, and seeming [11]. Furthermore, an adjunct is an element which has the function of telling us about the how, when, where or why of the situations expressed in a sentence [9]. Adjuncts are grouped into three main classes according to their function in the clause [15]. The first is Circumstantial Adjuncts, which provide the setting for the situation expressed in the clause, as regards place, time and manner, among others. The second is Stance Adjuncts, which express the speaker's attitude to or evaluation of the content of the clause and the third is Connective Adjuncts, which link two clauses, or parts of clauses, signalling the semantic relation holding between them, for example the phrase On the other hand.

\section{Simple Sentence}

Simple Sentence is a sentence that contains only one clause and that clause is an independent clause [16]. This independent clause can stand on its own with a complete meaning [14]. There are seven basic types of clause in English [17]; each type adds more elements one by one to the simple sentence.

Table 1. Codes and Themes

\begin{tabular}{lcl}
\hline No & Type & Example \\
\hline 1 & SP & A few people cannot sleep. \\
2 & SPA & The book is on the table. \\
3 & SPC & They have been full \\
4 & SPO & The Indonesian students should understand the English word classes. \\
5 & SPOA & The English language has a foreign status in Indonesia. \\
6 & SPOO & My uncle will give Mary a dictionary. \\
7 & SPOC & I imagined your aunt much fatter.
\end{tabular}

\section{Methodology}

Qualitative research is particularly good at answering the 'why', 'what' or 'how' questions and since the research question in this research is introduced by "what" and "how" [18], thus the writer has conducted the descriptive qualitative approach to do this research. It also can be seen through the data type used in this research which is qualitative data. The data will be the one clause sentences within an online news article taken from The Jakarta 
Post website. The writer focused on the article that was posted in October to November 2021. In gathering the data, documentation theory is applied, i.e. making the data as sequence of transcriptions [19]. Regarding this, the writer first went to The Jakarta Post's website and choses the news option "Indonesia" in it. The writer then downloaded the article and made the article as a transcript, which was arranged by its posting date. After making the article as a transcript, the writer picked up the sentence which was categorized as a simple sentence or that one clause sentence to be syntactically analysed. The analysing was done by using tree diagram [10], in order to know the sentence pattern's construction.

\section{Findings and Discussions}

Table 2. Sentence Pattern of one clause sentence found in The Jakarta Post Website's article

\begin{tabular}{llc}
\hline No & One Clause Sentence & Sentence Patterns \\
\hline 1 & On their last day of work on Thursday, employees lamented their exit. & ASPO \\
2 & The quake struck at a relatively shallow depth in the northeast of the town of Banjar Wanasari & SPA \\
3 & $\begin{array}{l}\text { More than } 300 \text { houses and 8o hectares of rice field in Padang Pariaman have been inundated. } \\
\text { The disasters are often caused by deforestation and poor mitigation planning, according to environmen- }\end{array}$ & SP \\
& SPCA \\
5 & Malists. & SPO \\
6 & Her long health workers have already received booster. & SPC \\
7 & $\begin{array}{l}\text { On Oct. 27, the student visited her lecturer in his office for a thesis consultation. } \\
8\end{array}$ & $\begin{array}{l}\text { On Oct. 5, 2020, millions of Indonesian workers suffered their worst defeat since the Reform Era with the } \\
\text { enactment of the omnibus Job Creation Law. }\end{array}$ \\
9 & He also controls shipping company PT Humpuss Intermoda Transportasi and other businesses. & ASPOA \\
\hline
\end{tabular}

Data 1. : From the data 01 "On their last day of work on Thursday, employees lamented their exit." The sentence pattern for this sentence is $\mathbf{A}+\mathbf{S}+\mathbf{P}+\mathbf{O}$, where the Adjunct contains Circumstantial Adjunct, which provides the information about time. Thus, the Adjunct of this sentence is "On their last day of work on Thursday". The Subject is "employees" because it precedes the verb. The Predicate is "lamented" because it includes the verb that describes the subject, and the Object is "their exit" because it is the thing that is affected by the action described in the predicate.

Data 2. : From the data 02 "The quake struck at a relatively shallow depth in the northeast of the town of Banjar Wanasari." The sentence pattern for this sentence is $\mathbf{S}+\mathbf{P}+\mathbf{A}$, where the Subject is "The quake" because it precedes the verb. The Predicate is "struck" because it includes the verb that describes the subject, and the Adjunct is "at a relatively shallow depth in the northeast of the town of Banjar Wanasari." because it provides the setting for the situation expressed in this sentence, namely place.

Data 3. : From the data 03 "More than 300 houses and 80 hectares of rice field in Padang Pariaman have been inundated." The sentence pattern for this sentence is $\mathbf{S}+\mathbf{P}$, where the Subject is "More than 300 houses and 80 hectares of rice field in Padang Pariaman" because it precedes the verb and the predicate is "have been inundated" because it includes the verb that describes the subject.

Data 4. : From the data 4 "The disasters are often caused by deforestation and poor mitigation planning, according to environmentalists." The sentence pattern for this sentence is $\mathbf{S}+\mathbf{P}+\mathbf{C}+\mathbf{A}$, where the Subject is "The disasters" because it precedes the verb. The Predicate is "are often caused" because it includes the verb that describes the subject, and the Complement is "by deforestation and poor mitigation planning" because it completes the meaning of the verbs and the Adjunct is "according to environmentalists" which contains Stance Adjunct that express the writer's attitude to or evaluation of the content of the sentence.

Data 5. : From data 05 "Many health workers have already received booster." The sentence pattern for this sentence is $\mathbf{S}+\mathbf{P}+\mathbf{0}$, where Subject is "Many health workers" because it precedes the verb. The Predicate is "have already received" because it includes the verb that describes the subject and the Object is "booster" because they are the things that are affected by the action described in the predicate.

Data 6. : From the data 06 "Her long skirt is made from single-use sachets of household items." The sentence pattern for this sentence is $\mathbf{S}+\mathbf{P}+\mathbf{C}$, where the Subject is "Her long skirt" because it precedes the verb. The Predicate is "is made" because it includes the verb that describes the subject, and the Complement is "from single-use sachets of household items" because it completes the meaning of the verbs. 
Data 7. : From the data 07 "On Oct. 27, the student visited her lecturer in his office for a thesis consultation." The sentence pattern for this sentence is $\mathbf{A}+\mathbf{S}+\mathbf{P}+\mathbf{O}+\mathbf{C}$, where the Adjunct is "On Oct. 27", which contains Circumstantial Adjunct, that provides the setting for the situation expressed in this sentence, namely time. The Subject is "the student" because it precedes the verb. The Predicate is "visited" because it includes the verb that describes the subject. The Object is "her lecturer in his office" because it is the thing that is affected by the action described in the predicate and the Complement is "for a thesis consultation" because it completes the meaning of the verbs.

Data 8. : From the data 08 "On Oct. 5, 2020, millions of Indonesian workers suffered their worst defeat since the Reform Era with the enactment of the omnibus Job Creation Law." The sentence pattern for this sentence is $\mathbf{A}+\mathbf{S}+\mathbf{P}+\mathbf{O}+\mathbf{A}, \mathbf{w h e r e}$ the Adjuncts are "On Oct. 5, 2020," and also "since the Reform Era with the enactment of the omnibus Job Creation Law" which called as a Circumstantial Adjunct because they provide the setting for the situation expressed in this sentence, namely the time. The Subject is "millions of Indonesian workers" because it precedes the verb. The Predicate is "suffered" because it includes the verb that describes the subject, and the Object is "their worst defeat" because it is the thing that is affected by the action described in the predicate.

Data 9. :From the data 09 "He also controls shipping company PT Humpuss Intermoda Transportasi and other businesses." The sentence pattern for this sentence is $\mathbf{S}+\mathbf{A + P + O}$, where the Subject is " $H e$ " because it precedes the verb. The adjunct is filled by an adverb "also". The Predicate is "controls" because it includes the verb that describes the subject, and the Object is "shipping company PT Humpuss Intermoda Transportasi and other businesses" because it is the thing that is affected by the action described in the predicate.

\section{Sentence Pattern Construction}

Table 3. Sentence Pattern Construction of One Clause Sentence Found in The Jakarta Post Website's Article

\begin{tabular}{lll}
\hline No & One Clause Sentence & Sentence Patterns \\
\hline 1 & ASPO & Prep P+NP+VP+NP \\
2 & SPA & NP+VP+Prep P \\
3 & SP & Compound NP+VP \\
4 & SPCA & NP+VP+Prep P+Prep P \\
5 & SPO & NP+VP+NP \\
6 & SPC & NP+VP+Prep P \\
7 & ASPOC & Prep P+NP+VP+NP+Prep P \\
8 & ASPOA & Prep P+NP+VP+NP+Prep P \\
9 & SAPO & NP+Adv P+VP+Compound NP \\
\hline
\end{tabular}

The construction of sentence pattern found in the data is manifold. The following are some representatives of tree diagram of the data above.

1. Subject construction, for instance in data 06 "Her long skirt".

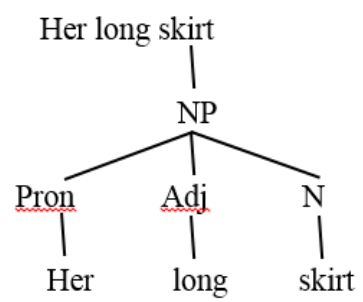

Figure 2. Subject construction, for instance in data 06 "Her long skirt".

The construction of the subject in this data is filled by a NP, where the phrase is filled by the combination of Pron "Her", Adj "long" and N "skirt".

2. Predicate construction, for instance in data 05 "have already received".

3. Object construction, for instance in data 09 "shipping company PT Humpuss Intermoda Transportasi and other businesses." 


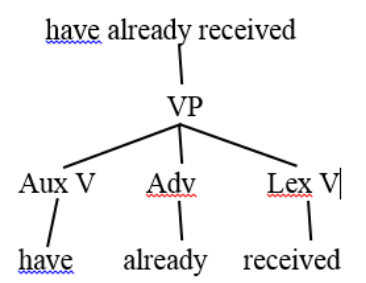

Figure 3. Predicate construction, for instance in data 05 "have already received".

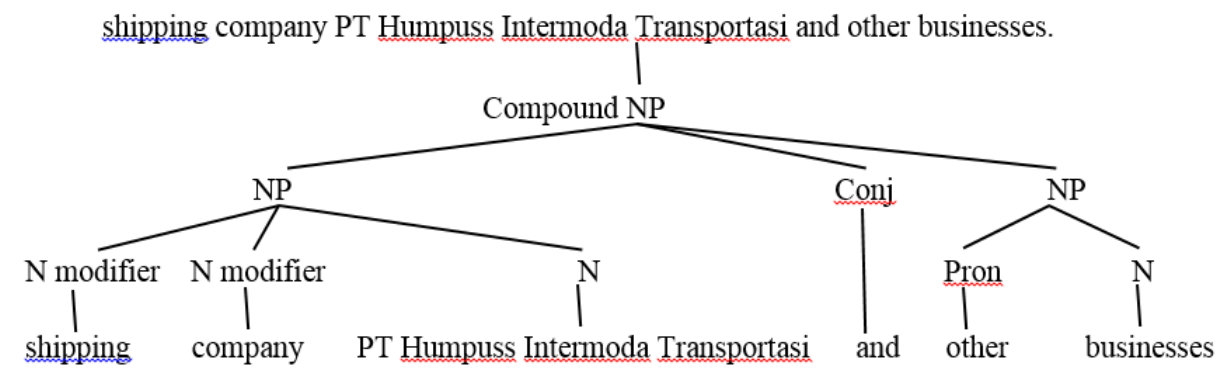

Figure 4. Object construction, for instance in data 09 "shipping company PT Humpuss Intermoda Transportasi and other businesses."

The construction of the Object in this data is filled by a Compound NP. This is a condition where two noun phrases are combined with a conjunction. The conjunction use in this sentence pattern is "and". The first NP is filled by the combination of N modifier "shipping" and "company" and N which it refer to a proper noun "PT Humpuss Intermoda Transportasi", whereas the other NP or the second NP is filled by the combination of Pron "other" and $\mathrm{N}$ "businesses".

4. Complement construction, for instance in data 07 "for a thesis consultation."

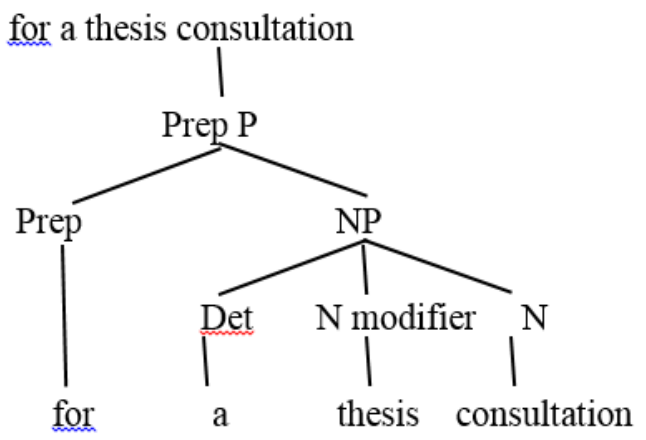

Figure 5. Complement construction, for instance in data 07 "for a thesis consultation."

The construction of the Complement in this data is filled by a Prep P, where the phrase is filled by the combination of Prep "for", and a NP "a thesis consultation", which consist of a Det "a", N modifier "thesis", and N "consultation". 5. Adjunct construction, for instance in data 04 "according to environmentalists".

The construction of the Adjunct in this data representative is filled by Prep P, where the Prep is "according to", followed by NP, which is filled by N "environmentalists".

\section{Conclusion}

Based on the sentence pattern definition, the writer found out 9 types of sentence patterns in the article taken from The Jakarta Post's website "Indonesia". Some of these sentence patterns involve the basic sentence pattern, namely SP, SPC, SPA, SPO, while the others are not. The other sentence patterns are ASPO, SAPO, SPCA, ASPOC, and ASPOA. The sentence construction of each data, based on the sentence pattern analysis using the tree diagram, an Adjunct of the data is filled by Prep P, and Adv P. The Prep P has preposition as head and followed by post modifier i.e. NP while 


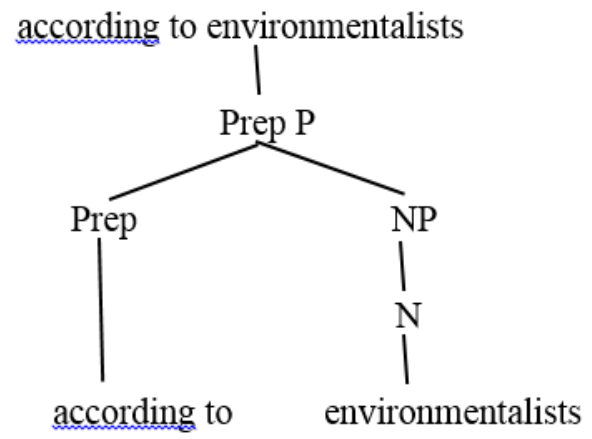

Figure 6. Adjunct construction, for instance in data 04 "according to environmentalists

the other Adjunct filled by Adv P consists only an adverb. The Prep P is the dominant phrase function as an Adjunct rather than Adv P. The other pattern within the sentence taken from the data such as Subject is filled mostly by NP and one another is filled by the combination of two NP, namely Compound NP, while the Complement from the data showed that it is filled only by Prep P. The NP can either have a pre and post modifier or not at all. In other words, the NP can be a single word, which consists only of the head. The Prep P is always preceded by Prep as the head, e.g. of, for, from, etc., and it is definitely followed by NP. Meanwhile, the Predicate definitely filled by VP, the modifiers found in the VP are Aux V and Adv P. Furthermore, on the Object, it is the same as the construction from the sentence pattern Subject, which is filled mostly by NP and another is filled by the combination of two NP, namely Compound NP.

\section{References}

[1] A. R. Yasmin, N. L. K. M. Indrawati, and N. K. S. Rahayuni. (2017, May). "Syntactic Analysis of Headline Structures in The Jakarta Post Online News." [Online]. Vol 19. Available: https://ojs . unud.ac.id/index.php/sastra/ article/view/29210/18113

[2] D. Luthfiyati, A. Kholiq, and I. N. Zahroh. (2017, December). "The Analysis of Word Formation Processes In The Jakarta Post Website." [Online]. Vol. 1. Available: https://media.neliti.com/media/publications/ 256372-the-analysis-of-word-formation-processes-ebb16fc6.pdf

[3] L. J. Brinton, The Structure of Modern English: A linguistics Introduction. Amsterdam: John Benjamins Publishing Company, 2000.

[4] V. Valin, An Introduction to Syntactic Theory and Analysis. Cambridge: Cambridge University Press, 2016.

[5] H. Koopman, D. Sportiche, and E. Stabler, An Introduction to Syntactic Analysis and Theory. Los Angeles: WileyBlackwell, 2013.

[6] M. B.Dalle, Fundamental of Language Research Methodology. Jakarta Pusat: Gunadarma Ilmu, 2016

[7] I. Purwarta, (2008). A Syntactic Analysis of the Sentence Pattern Used in Westlife Song's Lyric. (Thesis, Universitas Islam Negeri Malang, 2008) Accessed from: http://etheses.uin-malang.ac.id/4752/1/04320063.pdf

[8] H. Wekker, and L. Haegeman, A Modern Course in English Syntax. London: Routledge, 1996.

[9] B. Aarts, English Syntax and Argumentation, edition (second edition). New York: PALGRAVE, 2001.

[10] Coll, Language Files. Colombus: Ohio State University, 1991

[11] E. Ehrlich, and D. Murphy, Schaum's Outline of Theory and Problems of English Grammar , edition (second Edition). USA: McGrow-Hill Companies, 1991

[12] L. Rozakis, English Grammar for the utterly confused. USA: The McGraw-Hill Companies, 2003.

[13] M. Newson, et al., Basic English Syntax with Exercise. Budapest: Bolcsesz Konzorcium, 2006.

[14] M. Demirezen. (2012, February). "An Analysis of the Problem - Causing Structures of Simple Sentences for Turkish University Students." [Online] Vol. 2. Available : http://www . ijhssnet .com/journals/Vol_2_No_3_February_ 2012/19.pdf 
[15] A. Downing, and P. Locke, English Grammar: A University Course, edition (second edition). London: Routledge, 2006.

[16] Chandni, R. Narula, and S. K. Sharma. (2014, August-September). "Identification and Separation of Simple, Compound and Complex Sentences in Punjabi Language." [Online]. Vol. 6, Issue II, 123. Available: https: //www.ijcait.com/IJCAIT/62/623.pdf

[17] M. B. Dalle, and S. Halijah, "An Analysis of the Basic Clause Types of the Students' Syntactic Competence," In Global Conference on Teaching, Assessment, and Learning in Education (GC-TALE), Sanur, Bali, 2017.

[18] A. Lacey, and D. Luff, Qualitative Research Analysis. Sheffield: The NIHR RDS EM / YH, 2009.

[19] S. Arikunto, Metodelogi penelitian. Yogyakarta: Bina Aksara, 2006 